\section{Federation University ResearchOnline}

\section{https://researchonline.federation.edu.au}

Copyright Notice

This is the post-peer-review, pre-copyedit version of an article published in Engineering with Computers, the final authenticated version is available online at:

https://doi.org/10.1007/s00366-019-00711-6

Yang, H., \& Ramesh, M. (2020). Effects of a proper feature selection on prediction and optimization of drilling rate using intelligent techniques. Engineering with Computers, 36(2), 499-510.

Copyright @ 2020 Springer Nature Swtizerland AG. Part of Springer Nature 


\section{Engineering with Computers}

\section{Effects of a proper feature selection on prediction and optimization of drilling rate using intelligent techniques \\ --Manuscript Draft--}

\begin{tabular}{|l|l|}
\hline Manuscript Number: & EWCO-D-18-00737R1 \\
\hline Full Title: & $\begin{array}{l}\text { Effects of a proper feature selection } \\
\text { intelligent techniques }\end{array}$ \\
\hline Article Type: & Original Article \\
\hline Corresponding Author: & $\begin{array}{l}\text { haiqing yang } \\
\text { Chongqing University } \\
\text { Chongqing, Chongqing CHINA }\end{array}$ \\
\hline $\begin{array}{l}\text { Corresponding Author Secondary } \\
\text { Information: }\end{array}$ & Chongqing University \\
\hline Corresponding Author's Institution: & $\begin{array}{l}\text { Corresponding Author's Secondary } \\
\text { Institution: }\end{array}$ \\
\hline First Author: & Xiufeng Liao \\
\hline First Author Secondary Information: & Xiufeng Liao \\
\hline Order of Authors: & Manoj Khandelwal \\
\hline & Haiqing Yang, PhD \\
\hline & Mohammadreza Koopialipoor \\
\hline & Bhatawdekar Ramesh Murlidhar \\
\hline
\end{tabular}

Order of Authors Secondary Information:

Funding Information:

\begin{tabular}{ll} 
Abstract: & $\begin{array}{l}\text { One of the important factors during drilling times is the rate of penetration (ROP), which } \\
\text { is controlled based on different variables. Factors affecting different drillings are of } \\
\text { paramount importance. In the current research an attempt were made to better } \\
\text { recognize drilling parameters and optimize them based on an optimization algorithm. } \\
\text { To this purpose, 618 data, including RPM, flushing media, and compressive strength } \\
\text { parameters, were measured and collected. After initial investigation, the compressive } \\
\text { strength feature of samples, which is an important parameter from the rocks, was used } \\
\text { as a proper criterion for classification. Then using intelligent systems, three different } \\
\text { levels of the rock strength and all data were modeled. The results showed that systems } \\
\text { which were classified based on compressive strength showed a better performance for } \\
\text { ROP assessment due to the proximity of features. Therefore, these three levels were } \\
\text { used for classification. A new artificial bee colony algorithm was used to solve this } \\
\text { problem. Optimizations were applied to the selected models under different } \\
\text { optimization conditions, and optimal states were determined. As determining drilling } \\
\text { machine parameters is important, these parameters were determined based on optimal } \\
\text { conditions. The obtained results showed that this intelligent system can well improve } \\
\text { drilling conditions and increase the ROP value for } 3 \text { strength levels of the rocks. This } \\
\text { modeling system can be used in different drilling operations. }\end{array}$ \\
\hline $\begin{array}{ll}\text { Response Letter } \\
\text { Response to Reviewers: }\end{array}$ \\
\hline $\begin{array}{l}\text { Ref.: EWCO-D-18-00737 } \\
\text { Title: Effects of a proper feature selection on prediction and optimization of drilling rate } \\
\text { using intelligent techniques } \\
\text { To: Engineering with Computers }\end{array}$
\end{tabular}


Dear Editor,

I would like to thank you for giving us the opportunity to evaluate our paper with your expert and knowledgeable reviewers. The revised format of our paper is now ready based on the comments and advises of reviewers. In the revised manuscript, the changes are shown using red color. In addition, certificate of English proofreading service is attached as a figure. Our responses to the comments of reviewers can be seen in the following lines.

- Response to Reviewer \#1

- Response to Reviewer \#2

Thank you for your time and kind consideration.

Best regards,

Haiqing Yang

Corresponding author

Response to the reviewer \#1:

Dear Prof. / Dr.

I would like to appreciate your precise comments. Please consider our explanations and clarifications.

The literature study is quite nice as well as the quality of the research presented form the authors. Some more clarity is required though, in order to properly outline the decisions behind the implementation of the proposed modeling approach and to further illuminate its aspects. Some more issues for the authors to consider are:

Reply: Thank you very much for your time to review our paper and also for your positive feedback.

1. In section 3 the data is divided in two subsets (80-20). How was this made? Reply: Thank you for mentioning this point. We divided all data into two sections of training and testing ( $80 \%$ and $20 \%$, respectively) according to literature. Many researches mentioned that the best combination of train and test is $80-20$. Some researchers have suggested these percentages.

In the present study, 618 drilling data were measured at different thrust, RPM and flushing media on 6 different types of rock. Among them, 495 data sets ( $80 \%$ of all) were used for the training and testing of the ANN network, whereas 123 data sets ( $20 \%$ of all) were chosen for validation of the network.

-Hasanipanah M, Noorian-Bidgoli M, Jahed Armaghani D, Khamesi H (2016)

Feasibility of PSO-ANN model for predicting surface settlement caused by tunneling. Eng Comput 32: . doi: 10.1007/s00366-016-0447-0

-Hasanipanah M, Jahed Armaghani D, Bakhshandeh Amnieh H, et al (2016)

Application of PSO to develop a powerful equation for prediction of flyrock due to blasting. Neural Comput Appl. doi: 10.1007/s00521-016-2434-1

-Gordan B, Koopialipoor M, Clementking A, et al (2018) Estimating and optimizing safety factors of retaining wall through neural network and bee colony techniques. Eng Comput 1-10

2. In section 3 it is concluded that the optimum architecture of the ANN model is $4 \times 8 \times 1$, using one hidden layer with 8 neurons. As this is of crucial importance to the network's ability to generalize the details behind this selection should be included in the manuscript.

Reply: Thank you very much for mentioning this point. In Section 4, we provided a complete explanation of how to choose models, optimal conditions and the least error for the training and testing sections. Please see section 4 of the revised manuscript.

3. Is there a relationship between the number of neurons and iteration? Please explain. Reply: Thank you for your comment. These two mentioned parameters can evaluate the performance of intelligence models under different conditions. However, the relationship can not be described accurately. In general, number of neurons (input, 
output, hidden), are related to our datasets. For example, in our study, we considered thrust, RPM, flushing media and compressive strength as inputs to predict ROP. With these number of input, we can estimate number of hidden node, the maximum number of hidden node is equal to $2^{*}$ number of Input +1 . However, iteration number is related to system error. If we reach to the defined system error or the lowest one, the running system will be stopped. Normally, we use root mean square error as system error.

4. Please refer to the software package or code that is used for the ANN and the ANN$A B C$ models. Also please indicate how the data are passing from the ANN response to the $A B C$ for further processing.

Reply: Many thanks for these comments. We constructed this new network in the MATLAB environment. The training section was introduced as a function for the $A B C$ algorithm. This algorithm obtains the least errors for this function, and then the performance of the model improves.

5. Is the optimum number of fireflies relevant to the ANN structure? Please explain. Reply: Many thanks for this comment. Obtaining an optimal parameter value can increase the speed of implementing the ANN model. In this work, we also considered the model's accuracy to be the best mode for it. Optimizing stage is completely different with prediction through ANN. First an ANN model was developed and then the developed model was used in optimizing ROP through $A B C$ algorithm.

6. The following references are advised to be read and if necessary to be used for improvement of the state of the arts in the manuscript:

An intelligent based-model role to simulate the factor of safe slope

by support vector regression

Analysis of influential factors for predicting the shear strength of a V-shaped angle shear connector in composite beams using an adaptive neuro-fuzzy technique. Potential of soft computing approach for evaluating the factors affecting the capacity of steel-concrete composite beam.

An evolutionary fuzzy modelling approach and comparison of different methods for shear strength prediction of high-strength concrete beams without stirrups.

Computational Lagrangian Multiplier Method by using for optimization and sensitivity analysis of rectangular reinforced concrete beams.

Application of support vector machine with firefly algorithm for investigation of the factors affecting the shear strength of angle shear connectors

Application of ANFIS technique on performance of $C$ and $L$ shaped angle shear connectors.

Application of support vector machine with firefly algorithm for investigation of the factors affecting the shear strength of angle shear connectors.

Strength prediction of rotary brace damper using MLR and MARS

Reply: Many thanks. Based on your suggestion, we reviewed and added them in the revised manuscript.

Thank you for your time and kind consideration.

Best regards,

Haiqing Yang

Corresponding author

Response to the reviewer \#2:

Dear Prof. / Dr.

I would like to thank you for your constructive comments and time. We revised and improved our paper based on your comments. The following are our replies to your comments: 
In this study, a new methodology was developed to use data based on feature selection. The text of this research is completely written. This work presents a new method in the field of artificial intelligence and can be published in the journal. However, there are several points that authors should explain about them carefully: Reply: Thank you very much for your time and positive feedback.

1. Why did you select and use these performance indices? Why not other ones? Can another alternative be used?

Reply: Thank you. The use of statistical indices was in purpose of demonstration of the performance of intelligent models. Our used indices have been recommended by various scholars and due to that we used them.

- Safa M, Shariati M, Ibrahim Z, et al (2016) Potential of adaptive neuro fuzzy inference system for evaluating the factors affecting steel-concrete composite beam's shear strength. Steel Compos Struct 21:679-688

- Saemi M, Ahmadi M, Varjani AY (2007) Design of neural networks using genetic algorithm for the permeability estimation of the reservoir. J Pet Sci Eng 59:97-105 - Koopialipoor M, Fallah A, Armaghani DJ, et al (2018) Three hybrid intelligent models in estimating flyrock distance resulting from blasting. Eng Comput 1-14

2. Given that you used the prediction model for the ROP, it is suggested that you use numeric models for future work and develop your work.

Reply: We really appreciate your suggestion. Since the purpose of this paper is to predict and optimize ROP, we will follow your suggestion in near future.

3. Suggest to make section of 3.2 shorter. Because it can be found in literature. Reply: Thank you and done.

4. Why in the Table 1, the data is selected specifically? Please explain. Reply: Thank you. We added this point in the revised manuscript. We obtained data based on measurements and due to that reason they have different range.

5. Given the different models designed, can the effect of the number of features be considered important in the neural network? Explain.

Reply: Thank you for this comment. Feature selection can be one of the most important areas for improving the performance of neural networks. As noted in Section 4, there are various features, but the feature that has the most impact was chosen.

6. How do you justify about applicability of your results in practice and field? Reply: Thank you for this comment. Using software applications in the industry can help engineers and researchers. These new methods can be used as software.

7. Please explain how your proposed models can be used by the other researchers for project selection?

Reply: Thank you for this comment. We set different sections with optimal values in the text. Each step is explained in order to determine the main items. With these tips, researchers are able to develop their models with high performance prediction and low system error.

8. It is suggested to be careful about style of references.

Reply: Thank you very much and done. 
Thank you for your time and kind consideration.

Best regards,

Haiqing Yang

Corresponding author 
Click here to view linked References
1
2

\section{Cover Letter}
Date: 16 January, 2019
Subject: Submission of a revised manuscript for evaluation and publication

\begin{abstract}
Dear Editor,
I am enclosing herewith a revised manuscript entitled "Effects of a proper feature selection on prediction and optimization of drilling rate using intelligent techniques" for possible evaluation and publication in "Engineering with Computers". The helpful and constructive comments by the reviewer are greatly appreciated. The revised format of our paper is now ready based on the comments and advises of reviewer. As seen in the enclosed documents, the content of the manuscript has been rewritten entirely with better understanding and clearer concept.
\end{abstract}

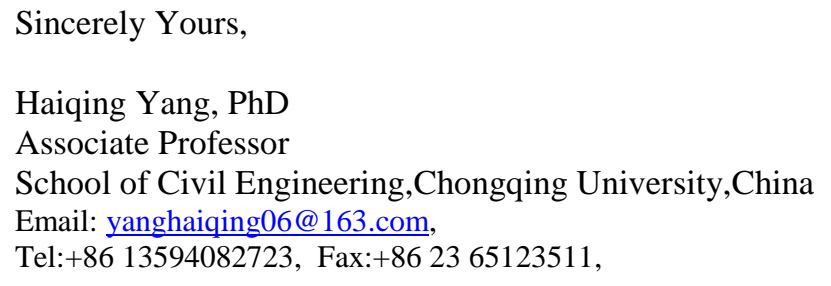




\section{Response Letter}

Ref.: EWCO-D-18-00737

Title: Effects of a proper feature selection on prediction and optimization of drilling rate using intelligent techniques

To: Engineering with Computers

Dear Editor,

I would like to thank you for giving us the opportunity to evaluate our paper with your expert and knowledgeable reviewers. The revised format of our paper is now ready based on the comments and advises of reviewers. In the revised manuscript, the changes are shown using red color. In addition, certificate of English proofreading service is attached as a figure. Our responses to the comments of reviewers can be seen in the following lines.

- Response to Reviewer \#1

- Response to Reviewer \#2

Thank you for your time and kind consideration.

Best regards,

Haiqing Yang

Corresponding author 


\section{Response to the reviewer \#1:}

Dear Prof. / Dr.

I would like to appreciate your precise comments. Please consider our explanations and clarifications.

The literature study is quite nice as well as the quality of the research presented form the authors. Some more clarity is required though, in order to properly outline the decisions behind the implementation of the proposed modeling approach and to further illuminate its aspects. Some more issues for the authors to consider are:

Reply: Thank you very much for your time to review our paper and also for your positive feedback.

\section{In section 3 the data is divided in two subsets (80-20). How was this made?}

Reply: Thank you for mentioning this point. We divided all data into two sections of training and testing (80\% and 20\%, respectively) according to literature. Many researches mentioned that the best combination of train and test is $80-20$. Some researchers have suggested these percentages.

In the present study, 618 drilling data were measured at different thrust, RPM and flushing media on 6 different types of rock. Among them, 495 data sets (80\% of all) were used for the training and testing of the ANN network, whereas 123 data sets ( $20 \%$ of all) were chosen for validation of the network.

- Hasanipanah M, Noorian-Bidgoli M, Jahed Armaghani D, Khamesi H (2016) Feasibility of PSO-ANN model for predicting surface settlement caused by tunneling. Eng Comput 32: . doi: 10.1007/s00366-016-0447-0

- Hasanipanah M, Jahed Armaghani D, Bakhshandeh Amnieh H, et al (2016) Application of PSO to develop a powerful equation for prediction of flyrock due to blasting. Neural Comput Appl. doi: 10.1007/s00521-016-2434-1

- Gordan B, Koopialipoor M, Clementking A, et al (2018) Estimating and optimizing safety factors of retaining wall through neural network and bee colony techniques. Eng Comput $1-10$ 
2. In section 3 it is concluded that the optimum architecture of the ANN model is 4x8x1, using one hidden layer with 8 neurons. As this is of crucial importance to the network's ability to generalize the details behind this selection should be included in the manuscript.

Reply: Thank you very much for mentioning this point. In Section 4, we provided a complete explanation of how to choose models, optimal conditions and the least error for the training and testing sections. Please see section 4 of the revised manuscript.

3. Is there a relationship between the number of neurons and iteration? Please explain.

Reply: Thank you for your comment. These two mentioned parameters can evaluate the performance of intelligence models under different conditions. However, the relationship can not be described accurately. In general, number of neurons (input, output, hidden), are related to our datasets. For example, in our study, we considered thrust, RPM, flushing media and compressive strength as inputs to predict ROP. With these number of input, we can estimate number of hidden node, the maximum number of hidden node is equal to $2 *$ number of Input +1 . However, iteration number is related to system error. If we reach to the defined system error or the lowest one, the running system will be stopped. Normally, we use root mean square error as system error.

4. Please refer to the software package or code that is used for the ANN and the ANN-ABC models. Also please indicate how the data are passing from the ANN response to the ABC for further processing. Reply: Many thanks for these comments. We constructed this new network in the MATLAB environment. The training section was introduced as a function for the $\mathrm{ABC}$ algorithm. This algorithm obtains the least errors for this function, and then the performance of the model improves.

\section{Is the optimum number of fireflies relevant to the ANN structure? Please explain.}

Reply: Many thanks for this comment. Obtaining an optimal parameter value can increase the speed of implementing the ANN model. In this work, we also considered the model's accuracy to be the best mode for it. Optimizing stage is completely different with prediction through ANN. First an ANN model was developed and then the developed model was used in optimizing ROP through ABC algorithm. 
6. The following references are advised to be read and if necessary to be used for improvement of the state of the arts in the manuscript:

An intelligent based-model role to simulate the factor of safe slope by support vector regression

Analysis of influential factors for predicting the shear strength of a V-shaped angle shear connector in composite beams using an adaptive neuro-fuzzy technique.

Potential of soft computing approach for evaluating the factors affecting the capacity of steel-concrete composite beam.

An evolutionary fuzzy modelling approach and comparison of different methods for shear strength prediction of high-strength concrete beams without stirrups.

Computational Lagrangian Multiplier Method by using for optimization and sensitivity analysis of rectangular reinforced concrete beams.

Application of support vector machine with firefly algorithm for investigation of the factors affecting the shear strength of angle shear connectors

Application of ANFIS technique on performance of $\mathrm{C}$ and $\mathrm{L}$ shaped angle shear connectors. Application of support vector machine with firefly algorithm for investigation of the factors affecting the shear strength of angle shear connectors.

Strength prediction of rotary brace damper using MLR and MARS

Reply: Many thanks. Based on your suggestion, we reviewed and added them in the revised manuscript.

Thank you for your time and kind consideration.

Best regards,

Haiqing Yang

Corresponding author 


\section{Response to the reviewer \#2:}

Dear Prof. / Dr.

I would like to thank you for your constructive comments and time. We revised and improved our paper based on your comments. The following are our replies to your comments:

In this study, a new methodology was developed to use data based on feature selection. The text of this research is completely written. This work presents a new method in the field of artificial intelligence and can be published in the journal. However, there are several points that authors should explain about them carefully:

Reply: Thank you very much for your time and positive feedback.

1. Why did you select and use these performance indices? Why not other ones? Can another alternative be used?

Reply: Thank you. The use of statistical indices was in purpose of demonstration of the performance of intelligent models. Our used indices have been recommended by various scholars and due to that we used them.

- Safa M, Shariati M, Ibrahim Z, et al (2016) Potential of adaptive neuro fuzzy inference system for evaluating the factors affecting steel-concrete composite beam's shear strength. Steel Compos Struct 21:679-688

- Saemi M, Ahmadi M, Varjani AY (2007) Design of neural networks using genetic algorithm for the permeability estimation of the reservoir. J Pet Sci Eng 59:97-105

- Koopialipoor M, Fallah A, Armaghani DJ, et al (2018) Three hybrid intelligent models in estimating flyrock distance resulting from blasting. Eng Comput 1-14

2. Given that you used the prediction model for the ROP, it is suggested that you use numeric models for future work and develop your work. 
Reply: We really appreciate your suggestion. Since the purpose of this paper is to predict and optimize ROP, we will follow your suggestion in near future.

3. Suggest to make section of 3.2 shorter. Because it can be found in literature.

Reply: Thank you and done.

4. Why in the Table 1, the data is selected specifically? Please explain.

Reply: Thank you. We added this point in the revised manuscript. We obtained data based on measurements and due to that reason they have different range.

5. Given the different models designed, can the effect of the number of features be considered important in the neural network? Explain.

Reply: Thank you for this comment. Feature selection can be one of the most important areas for improving the performance of neural networks. As noted in Section 4, there are various features, but the feature that has the most impact was chosen.

6. How do you justify about applicability of your results in practice and field?

Reply: Thank you for this comment. Using software applications in the industry can help engineers and researchers. These new methods can be used as software. 
7. Please explain how your proposed models can be used by the other researchers for project selection? Reply: Thank you for this comment. We set different sections with optimal values in the text. Each step is explained in order to determine the main items. With these tips, researchers are able to develop their models with high performance prediction and low system error.

8. It is suggested to be careful about style of references.

Reply: Thank you very much and done.

Thank you for your time and kind consideration.

Best regards,

Haiqing Yang

Corresponding author 
Click here to view linked References

\title{
Effects of a proper feature selection on prediction and optimization of drilling rate using intelligent techniques
}

\author{
Xiufeng Liao ${ }^{1}$, Manoj Khandelwal ${ }^{2}$, Haiqing Yang*33 ${ }^{*}$ Mohammadreza Koopialipoor ${ }^{4}$, \\ Bhatawdekar Ramesh Murlidhar ${ }^{5}$ \\ ${ }^{1}$ Construction project quality supervision station, Hechuan Chongqqing, China 401520. Email: \\ 17877212@qq.com. \\ ${ }^{2}$ School of Engineering and Information Technology, Faculty of Science and Technology, Federation \\ University Australia, PO Box 663, Ballarat, Victoria 3353, Australia. Email: \\ m.khandelwal@federation.edu.au. \\ 3*Associate Professor, School of Civil Engineering, Chongqing University, Chongqing, China \\ 400045. Email: yanghaiqing06@163.com. Tel:+86 13594082723, Fax:+86 2365123511 , \\ (Corresponding Author).
}

${ }^{4}$ Faculty of Civil and Environmental Engineering, Amirkabir University of Technology, 15914, Tehran, Iran. E-mail: Mr.koopialipoor@aut.ac.ir.

${ }^{5}$ Geotropik- Centre of Tropical Geoengineering, Universiti Teknologi Malaysia, Skudai 81310, Johor, Malaysia. Email: rmbhatawdekar@gmail.com. 


\begin{abstract}
One of the important factors during drilling times is the rate of penetration (ROP), which is controlled based on different variables. Factors affecting different drillings are of paramount importance. In the current research an attempt were made to better recognize drilling parameters and optimize them based on an optimization algorithm. To this purpose, 618 data, including RPM, flushing media, and compressive strength parameters, were measured and collected. After initial investigation, the compressive strength feature of samples, which is an important parameter from the rocks, was used as a proper criterion for classification. Then using intelligent systems, three different levels of the rock strength and all data were modeled. The results showed that systems which were classified based on compressive strength showed a better performance for ROP assessment due to the proximity of features. Therefore, these three levels were used for classification. A new artificial bee colony algorithm was used to solve this problem. Optimizations were applied to the selected models under different optimization conditions, and optimal states were determined. As determining drilling machine parameters is important, these parameters were determined based on optimal conditions. The obtained results showed that this intelligent system can well improve drilling conditions and increase the ROP value for 3 strength levels of the rocks. This modeling system can be used in different drilling operations.
\end{abstract}

Keywords: Compressive strength feature; ROP; Optimization; ABC. 


\section{1- Introduction}

Drilling is one of the most crucial processes in excavation industry, starting from exploration stage and continuing at every phase of production, till completion of mining activity [1]. Drilling has important role in mining as well as petroleum industry to reduce excessive costs and subsequently to enhance effectiveness of project [2]. Of the various purposes for which the rock is drilled, drilling takes a unique place due to its wider applications in civil purpose, e.g. transport, hydro, power, etc. Rotary drilling is a three dimensional cutting operation involve a combination of one or several cutting processes commonly known as indentation [3-5], cutting and crushing [6], ploughing, grinding and shearing [7]. However, the rock fragmentation at the bit rock interface is a combined action of thrust force as well as torque compound.

Drilling penetration rate is influenced by machine design related parameters, geological conditions and geotechnical properties of rocks [8]. Drilling machine parameters can be controlled, but the geological conditions and geotechnical properties of rocks cannot be altered. Rate of penetration (ROP) is influenced by many variables that comprise controllable as well as uncontrollable parameters. The bit diameter and type, the rotational speed, the blow frequency, the thrust, and flushing rate are the controllable parameters, whereas the rock properties and geological conditions are uncontrollable parameters. These typical factors affect ROP in diverse means [9]. Penetration rate $(\mathrm{PR})$ or Rate of penetration (ROP) is expressed in $\mathrm{m} / \mathrm{h}$ and refers to the linear meter excavation per unit time [10]. Having some prior knowledge of the TBM penetration rate in rock excavation projects is very helpful to plan construction time and to control cost. Penetration rate prediction is considered as a complex and difficult work because of the interaction between rock mass and drill 
machine, but a meaningful task because it is significant for time planning, cost control and choosing the excavation method [11].

The performance improvement in penetration rate of drill can improve the overall economics of the project. This includes improvement in penetration rate and life of bit or decrease in bit wear rate. In order to reduce the drilling cost, investigations in the past have been carried out to reach at suitable working level of machine parameters for particular rock type. The detailed study for the relationship between the rate of penetration and various rock as well as machine parameters are carried out by numerous researchers $[3,4,12,13]$. However, the work in this regard has not considered all machine parameters and has been confined to laboratory tests only.

To study the influence of various parameters on the performance of drilling, various researchers work have been reviewed $[5,12,14-17]$ and found that the rate of penetration increases linearly with the increase of thrust on bit for each rotational speed. However, for each rpm there exists an optimum thrust on bit and beyond which there is no appreciable increase in rate of penetration. The magnitude of torque developed at the bit rock interface increases linearly with the increase of the thrust on bit at each rotational speed.

Since, most of the investigations are empirical in nature and therefore, their application has not made universal. In order to know a greater applicability of these characteristics in the drilling, a lot of work has been carried out to find and suggest a definite model, which can be rock friendly. On the basis of detailed investigation, a viable approach for the prediction is necessary, and an Artificial Intelligence (AI) comes in handy to fulfill this approach.

Methodology of artificial intelligence (AI) for application for civil and mining engineering projects have been represented with examples [18, 19, 28-35, 20-27]. When type of inputs and outputs are not known including their nature for resolving a problem, the same can be solved quickly through 
artificial neural network (ANN) which is section of AI [36, 37]. Inputs and output(s) in a given problem is connected through non-linear function which is designed through ANN. Relations are produced between inputs and outputs based on sample data by ANN connected with non-linear function. With the support of activation function and weights between different sample data set, the established relations are utilized for subsequent sample data set [38]. Any eminent algorithm is not available for connecting between inputs and outputs with dynamic conditions. While above mentioned networks have played important role in uncertain conditions.

An algorithm which is optimized based on simulation of raw behavior of bee is either on their foraging behavior or breeding process. The problems requiring combinatorial optimization are solved using algorithms on the basis of process connected with mating for life reproduction. On the other hand, many problems requiring optimized solution are obtained through algorithms based on simulation of honeybees' nature of foraging behavior. The Bee Colony Optimization [39, 40], Virtual Bee [40], Bee [41] and Artificial Bee Colony [42, 43] are various algorithms developed on the basis of behavior of honeybee swarms which is foraging in nature. Even though complete set of bee algorithms have standard characteristics, every algorithm differs in certain features. The problem of travelling salesman was solved by developed algorithm of Bee Colony Optimization (BCO) by Teodorovic and co-workers [39, 40]. Various numerical examples were also solved by BCO. Additionally, some more potential problem areas of traffic engineering and transportation were identified for solving using $\mathrm{BCO}$ algorithm. Intelligent principles used by Swarm for developing the $\mathrm{BCO}$ algorithm was useful to solve problems in engineering which are complex in nature as reported by Teodorovic [39]. Yang [44] suggested the Virtual Bee Algorithm (VBA) and established methodology to solve numerical problems which are two dimensional in characteristics using VBA. Yang [44], on the basis of his judgment, he concluded that VBA was as productive as 
genetic algorithms. He further stated that VBA was efficient as compared to a conventional algorithm for optimization by virtue of multiple agents working in parallel. Pham et al. [41] recommended the Bee Algorithm (BA) initially. BA is utilized for resolving optimization problems in unconstrained function. BA is also useful in training perceptron networks which are multilayered to identify various patterns in control charts. They further asserted that BA usually provides more excellent results as compared to the GA and ant colony algorithm which is due to higher speed to optimize and correctness in outcome. One of disadvantage of BA algorithm is that many parameters are to be initiated before BA algorithm is executed. The Artificial Bee Colony (ABC) algorithm was suggested by Karaboga and Basturk [45]. The problems of constrained and unconstrained function were optimized using $\mathrm{ABC}$ algorithm. The results achieved using $\mathrm{ABC}$ algorithm were evaluated by Karaboga and Basturk. They announced that ABC produced better results as compared to particle swarm optimization and an evolutionary algorithm or differential evaluation. For solving engineering problems, an evolutionary algorithm produced better results and can be deployed efficiently. In recent times, Singh [46] for solving leaf- constrained discrete problems which are optimized consisting of least possible spanning tree utilized the $A B C$ algorithm. Optimization of ant colony algorithm, genetic algorithm and tabu search algorithm were compared with the $\mathrm{ABC}$ algorithm. Singh recommended that $\mathrm{ABC}$ algorithm which is newly developed performed the best results as compared to various ways and provided solutions in shorter time with a quality. In this research, an essential feature of the data was extracted. Then, various parameters were used to define a meaningful relationship. Finally, optimization models for ROP were obtained. 


\section{Data collection}

In the present study, 618 drilling data were measured at different thrust, RPM and flushing media on 6 different types of rock. Among them, 495 data sets (80\% of all) were used for the training and testing of the ANN network, whereas 123 data sets (20\% of all) were chosen for validation of the network. The thrust was kept at seven different levels, viz. 325, 410, 490, 560, 641, 728 and $820 \mathrm{~N}$, whereas RPM was kept constant at four different levels 285, 471.1, 687.1 and 1122.2 for each rock type. Plain tap water with poly-ethylene-oxide (PEO) mixed with different ppm was used for the measurement of ROP. PEO mixed with water was kept at four different levels, viz. 0, 10, 15, 20 and $30 \mathrm{ppm}$. In this, plain tap water is considered as a zero ppm. Flushing rate of 285 1/min was kept constant for the whole study.

Six different rock types were used for this analysis, namely, sandstone, limestone, rock phosphate, dolomite, marble and quartz-chloride-schist. In this study, 120 drilling data sets were measured on sandstone, 124 on limestone, 128 on rock phosphate, 139 on dolomite, 56 on marble and 51 on quartz-chloride-schist. The statistical data for the whole of the data is presented in Table 1.

Table 1 A view of All Data

\begin{tabular}{ccccc}
\hline Parameter & Unite & Max & Min & Average \\
\hline Thrust & $\mathrm{N}$ & 820 & 325 & 547.95 \\
RPM & Rad/min & 1122 & 285 & 632.74 \\
flushing media & $1 /$ min & 30 & 0 & 13.58 \\
compressive & $\mathrm{MPa}$ & 77.8 & 24.5 & 45.36 \\
strength & & & & \\
\hline
\end{tabular}




\section{Methods}

\subsection{Artificial Neural Network (ANN)}

With an objective of data transmission to solve science and engineering problems, ANNs are treated as approximate resemblance mechanism which are motivated by human brain. It is commonly accepted conditions that whenever there is complicated and not linear correlation between input sample data and output of model, most suitable applications depend upon ANNs [47-49]. Several categories of ANNs have been suggested and multilayer feed-forward (FF) ANNs are very common which are connected with different weights having multiple layers linked to many hidden nodes (neurons) $[50,51]$. Learning algorithms is must for ANNs for training purpose in order to find approximate solution. In order to train ANNs, the most commonly adapted algorithm is the back-propagation (BP) [34, 52-54]. For minimizing model error between goal standards (acquired by the system) and output, BP algorithm is most suitable. Whenever the error of model is greater than predefined error for example root mean square error (RMSE), the network weights are adjusted by the system through back propagation. Figure 1 shows outlook of structure of BP-ANN model. 
Forward Propagation

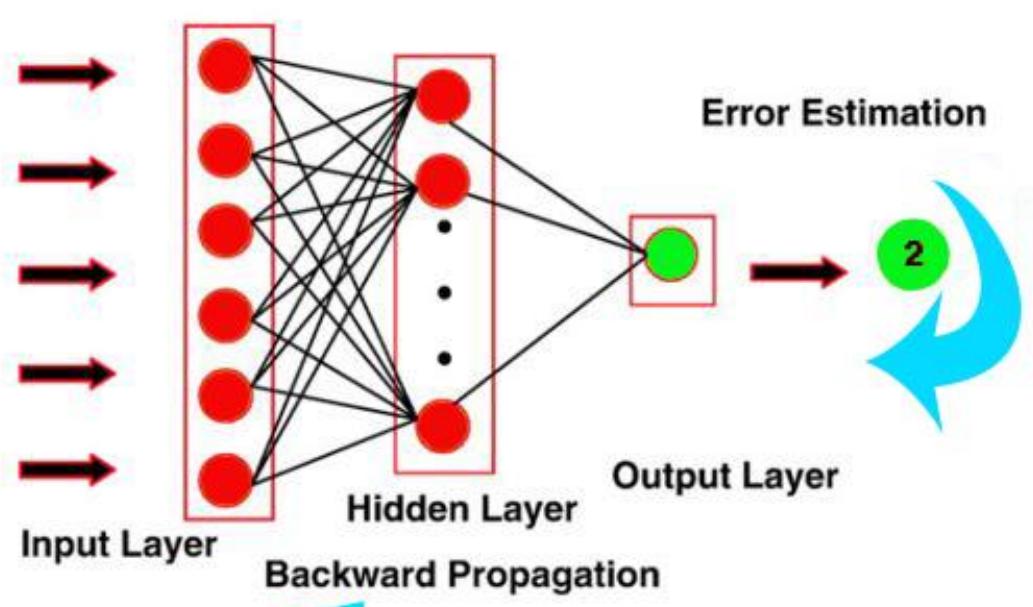

Figure 1 Outlook of structure of BP-ANN model [55]

\subsection{Artificial Bee Colony}

Motivated on the basis of life of bees Karaboga [56] created the ABC algorithm which was optimized where every bee is elementary constituent. If these elementary constituents make arrangements for a colony of bees binding together, even though their behavior will be complicated but still understandable to produce integrated system and bunch of flowers containing sweet honey drink can be exploited. Every colony of bees having three groups of bees and each group has to perform different duty. Scout bees are the first group whose task is to discover new sources. The scout bees concentrate on core honey bearing environment and may not explore external environment. Information on food is collected and stored in memory of scout bees. When every scout bee returns to hive, information on food source is shared through a waggle dance. The employed bees are second group whose responsibility consists of exploiting the food source based 
information shared during waggle dance based on memory of scout bees. Onlooker bees are the third group in hive. They wait for second group of bees to return to hive and during waggle dance they gather information on suitability and fitness of food source and concentrate to exploit one resource at a time. Several mathematical problems, industrial and engineering issues are solved using this algorithm $[18,57]$.

The major four steps of the $\mathrm{ABC}$ algorithm are stated below [43]:

Step 1:

On the first occasion, in the $\mathrm{ABC}$ algorithm, $50 \%$ of the bees' community are employed bees and the balance 50\% are non-employed bees. For each supply point of honey, the employed bees consist of one batch only. Alternatively, the total employed bees are equivalent to total supply point of honey surrounding the hive. Thus, an employed bee is assigned to each supply point of honey, which implies that total supply point of honey produces basic solution which is within range of possible solutions. Once basic solution is produced, problem linkage must be utilized to find out the amount for every solution.

Step 2:

In the present portion of the program, for every problem solution, a fresh answer is produced utilizing the linkage:

$v_{i, j}=x_{i . j}+\varphi_{i . j}\left(x_{i . j}-x_{k . j}\right)$

$i \in\{1.2 . B N\}$

$j \in\{1.2 \ldots D\}$

$k \in\{1.2 \ldots . . B N\} \& k \neq i$ 


$$
\varphi \in[-1.1]
$$

where $x_{i . j}$ is derived from the answer $\mathrm{i}$ using the dimension $\mathrm{j}$,

$v_{i, j}$ is dimension $\mathrm{j}$ in the fresh answer, $\mathrm{i}$ is the number one answer among various answers to the problems,

$\varphi$ is a random number in the negative interval of one to one,

$\mathrm{k}$ is a random number produced among various answers to the problem,

$\mathrm{BN}$ is the number of introductory answers for the problem, and

$\mathrm{D}$ is the number of dimensions to be optimized.

After producing a fresh answer, if the amount of this answer is more than the amount of the former answer, it will be restored, alternatively the present answer will be abandoned.

Step 3: During this phase, the probability of gathering bees from every site is computed by the equation given below:

$$
p_{i}=\frac{f i t_{i}}{\sum_{n=1}^{S N} f i t_{n}}
$$

where the fitness of source $\mathrm{i}$ is $f_{i t}$ and the onlooker bees selecting source $\mathrm{i}$ depends upon the probability $p_{i}$. On the basis of fitness of every item, allocation of total bees is decided. During this phase, on the basis of fitness all the bees may be allocated to honey source. A fresh answer is created among various picked up answers by utilizing equation (1) by computing the value of every honey source. If fresh answer gets better value than prior answer, fresh answer will succeed the prior answer or alternatively fresh answer will be improvised. The objective of improvising answer 
is for making a tally for the number of failures to enhance the response, and if answer is not upgraded, one entity will be added to it.

Step 4: During this phase, if the tally count of non-improvising answer turns up to pre-specified limitation (Cmax), fresh answer will be succeeded by a random answer. During this phase, surrounding circumstances of end of repetitions are also scrutinized. Repetitions will finish if circumstances of end conditions are found as per the algorithm, alternatively it will restore to step two. Various researchers have elaborated on ABC structure including working of the same $[42$, 43, 56]. Outlook of ABC algorithm is given in Figure 2. 


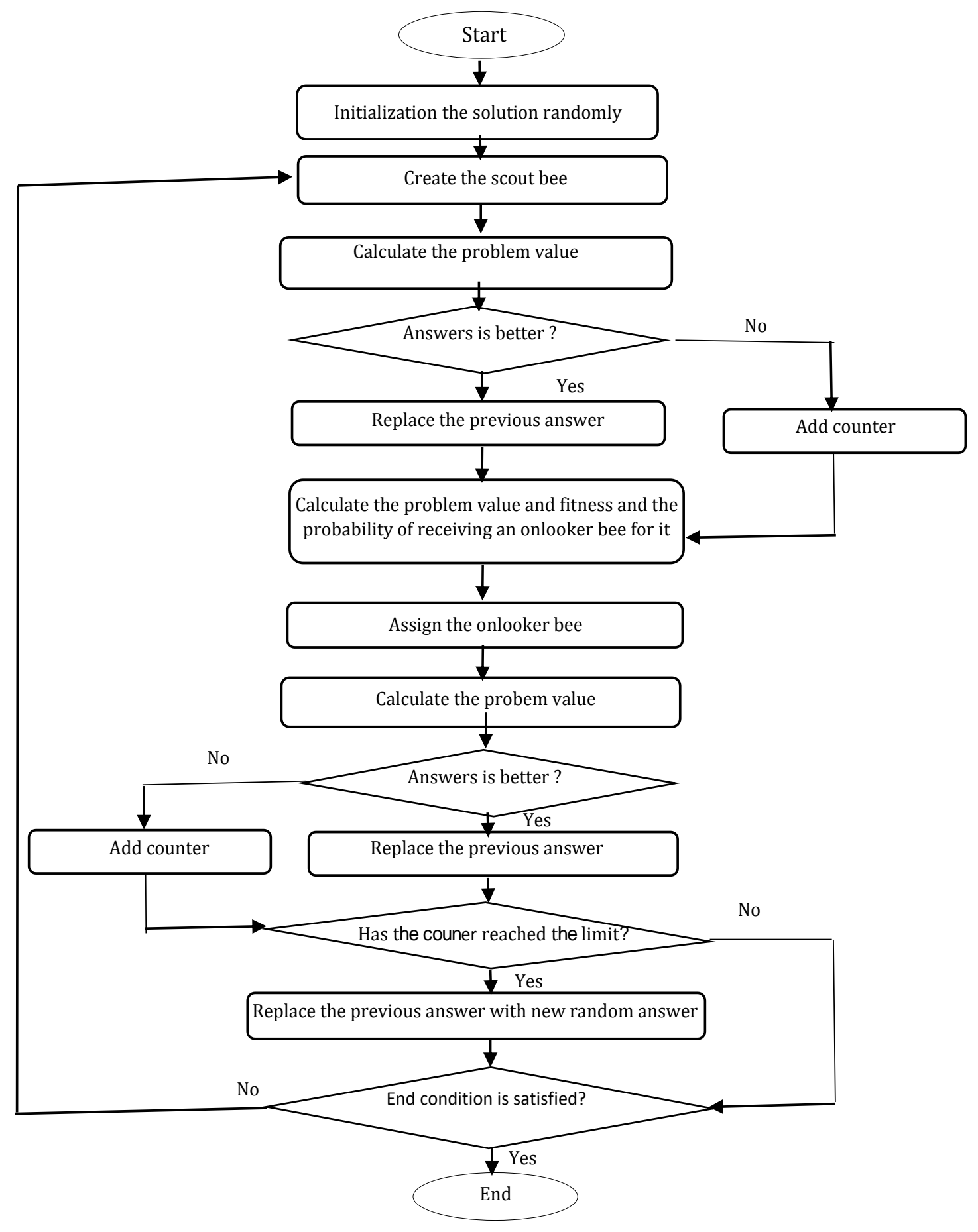

Figure 2 Outlook of $\mathrm{ABC}$ algorithm to optimize the ROP [57] 


\section{Result and Discussion}

\subsection{Initial Classification}

In the current research 618 data from different samples were collected and measured. The precise investigation of parameters affecting ROP can provide a useful aid for drilling in different types of rocks. As shown in Table 1, 4 parameters including compressive strength, thrust, RPM, and flushing media, were assessed for all samples. As each parameter affects ROP, the correct choice of these parameters can produce more precise results in calculations and modeling. Three parameters: thrust, RPM, and flushing media are related to the characteristics of drilling machine and the compressive strength parameter was used from different investigated and measured rocks. As aforementioned, compressive strength parameter is among the main characteristics of rocks, which has the main effect on drilling and ROP. For this reason, in this research, at first, all parameters were divided into some groups based on their strength level. Figure 3 displays different values of compressive strength for all samples. 


\begin{abstract}
As seen, the compressive strength range is divided into three groups of low (128 samples), medium
\end{abstract} (439 samples), and high (49 samples). This classification was done so that we can present the appropriate models of ROP for different strength levels. Given the conducted studies, in the following, different models for ROP assessment are presented and discussed for all data as well as three levels of data which were classified based on their strength.

\title{
4.2 Modeling of Predictive systems
}

In the present study, problem was solved using Perceptron ANNs due the complexity of the problem. Learning of the ANN was done based on the learning function of the MarkvartLevenberg. On the established methodology of many researchers, selection of the number of layers in neural network model was carried out $[31,36,58]$. These layers consist of input, output and 
hidden layers. Input layer in this study is considered as 4 nodes, while output layer is set as one output. According to $[59,60]$, any non-linear function can be solved by a hidden layer. Various research works have been done for selecting suitable number of neurons in hidden layers. Trial and error methodology needs to be adopted for fitting correct number of hidden neurons.

The number of iterations and neurons are considered as two important parameters in neural network designing. Therefore, the effect of these parameters was investigated on all data and three levels. The values proposed by previous researchers were investigated for the number of neurons between 1 and 10 and the number of iterations between 20 and 100. Using this method, one can obtain a more precise estimation of conditions as well as the models results. The results from prediction models based on $\mathrm{R}^{2}$ and RMSE are presented in Figures 4-7.

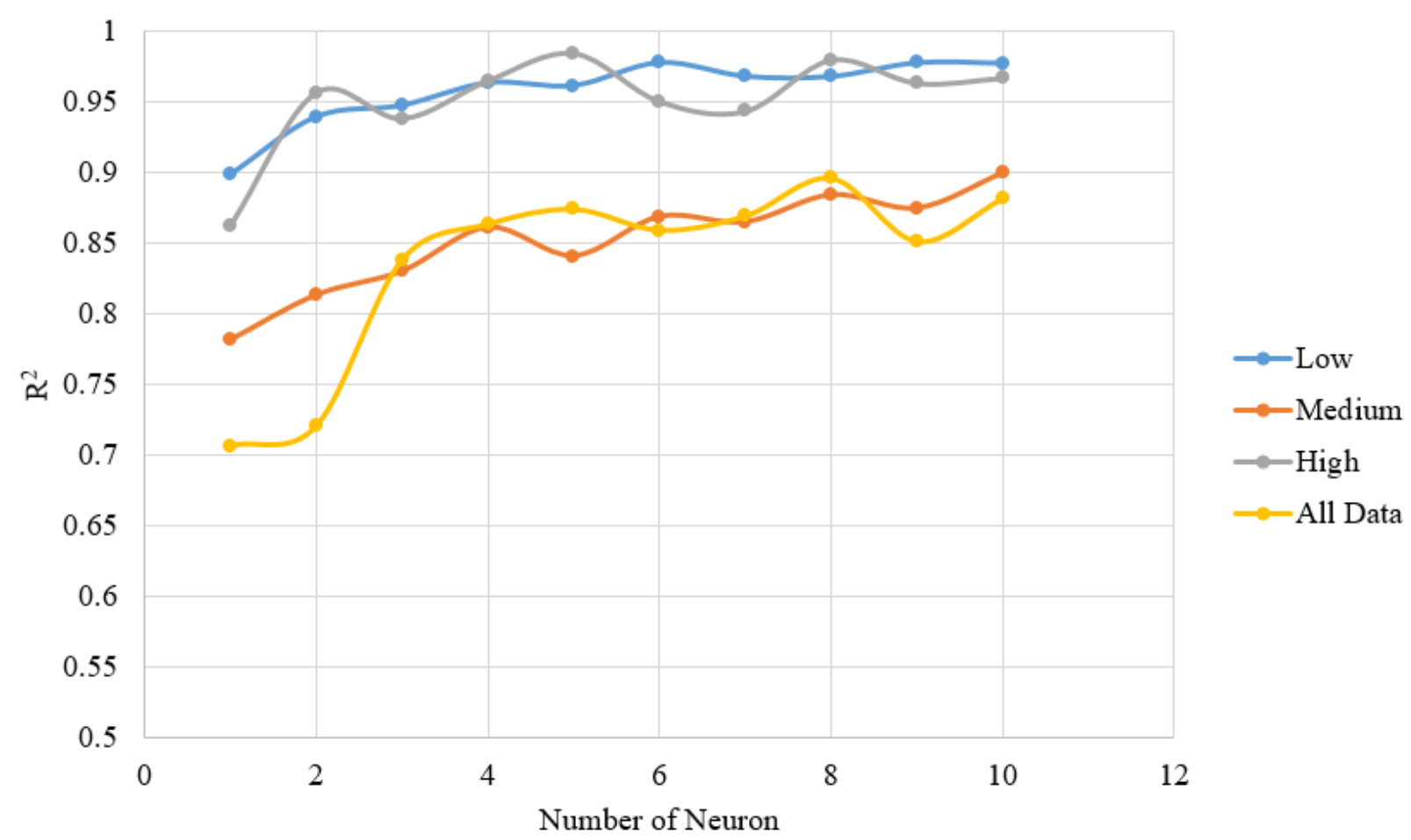

Figure 4 The results of prediction models based on the number of neurons in terms of $\mathrm{R}^{2}$ 


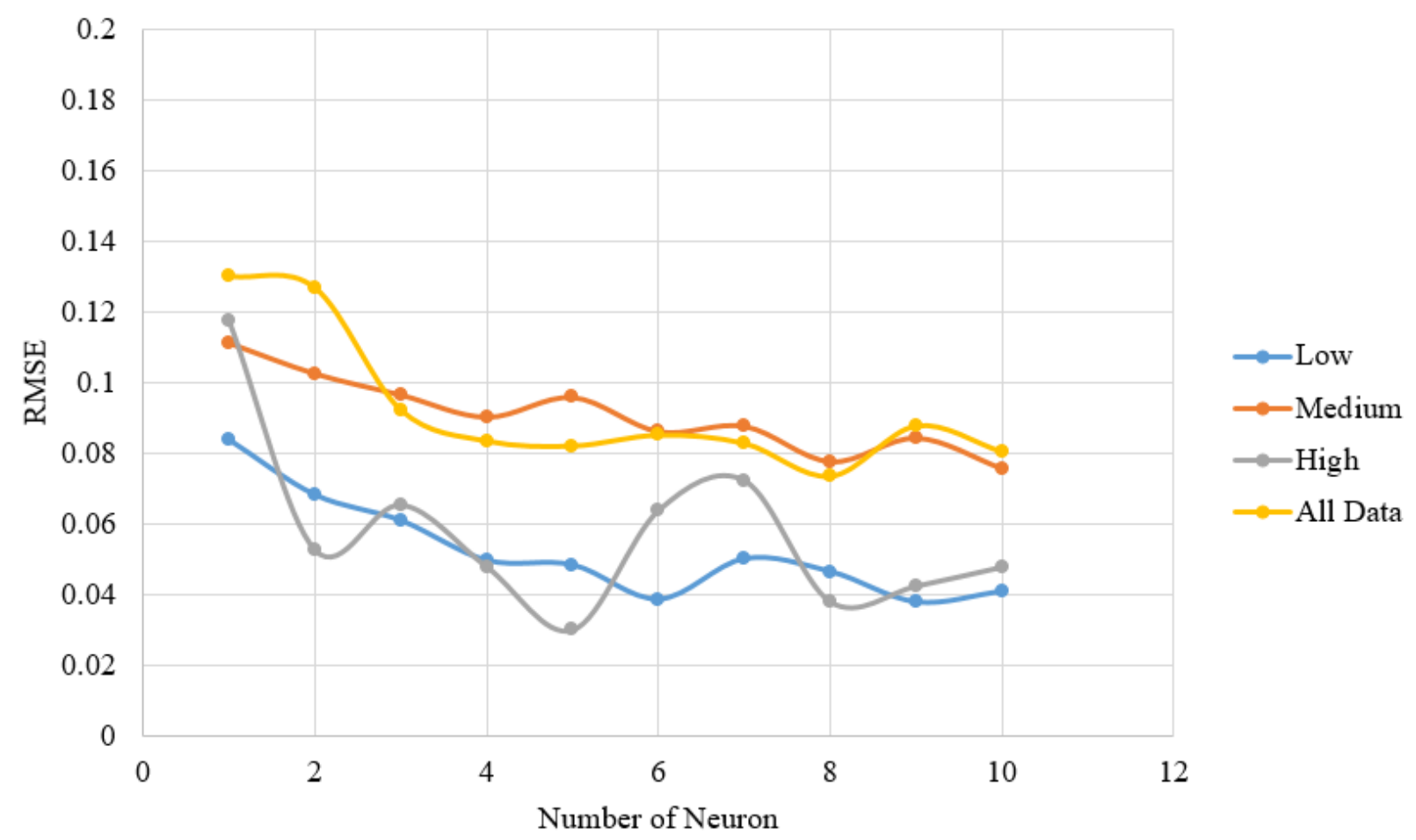

Figure 5 The results of prediction models based on the number of neurons in terms of RMSE

As shown in Figure 4, the number of neurons has significantly increased $\mathrm{R}^{2}$ values. As the number of neurons increases, an increasing trend can be seen in $\mathrm{R}^{2}$ values. Choosing the state presenting the most optimal result of prediction can take priority. Additionally, Figure 5 shows the decreasing trend in system errors. Overall, increasing the number of neurons leads to obtaining better models with higher performance prediction. In these conditions, a number of 8 neurons for the whole data is the best and the most optimal state of prediction. In order to select 3 strength levels, the values 5, 10, and 6 were selected for the high, medium, and low levels.

Another comparison that can be made using Figures 4 and 5 is to investigate the results of these 4 groups of modeling. Considering that all data were investigated besides 3 groups, which have been divided based on strength, one can better recognize the results of analysis. As seen, dividing data 
based on strength, which is directly dependent on the rock conditions, presents generally a better criterion. In these conditions, the use of models capable of presenting predictions simply and for different conditions can provide better conditions during drilling and a proper rate of ROP. However, this process is suggested so that better conditions can be provided for optimization through its precise investigation.

Figure 6 and 7 display the results for the investigation of the number of repetitions for $\mathrm{R}^{2}$ and RMSE. Considering the points mentioned in the previous section, their optimal selection can affect the program's run time.

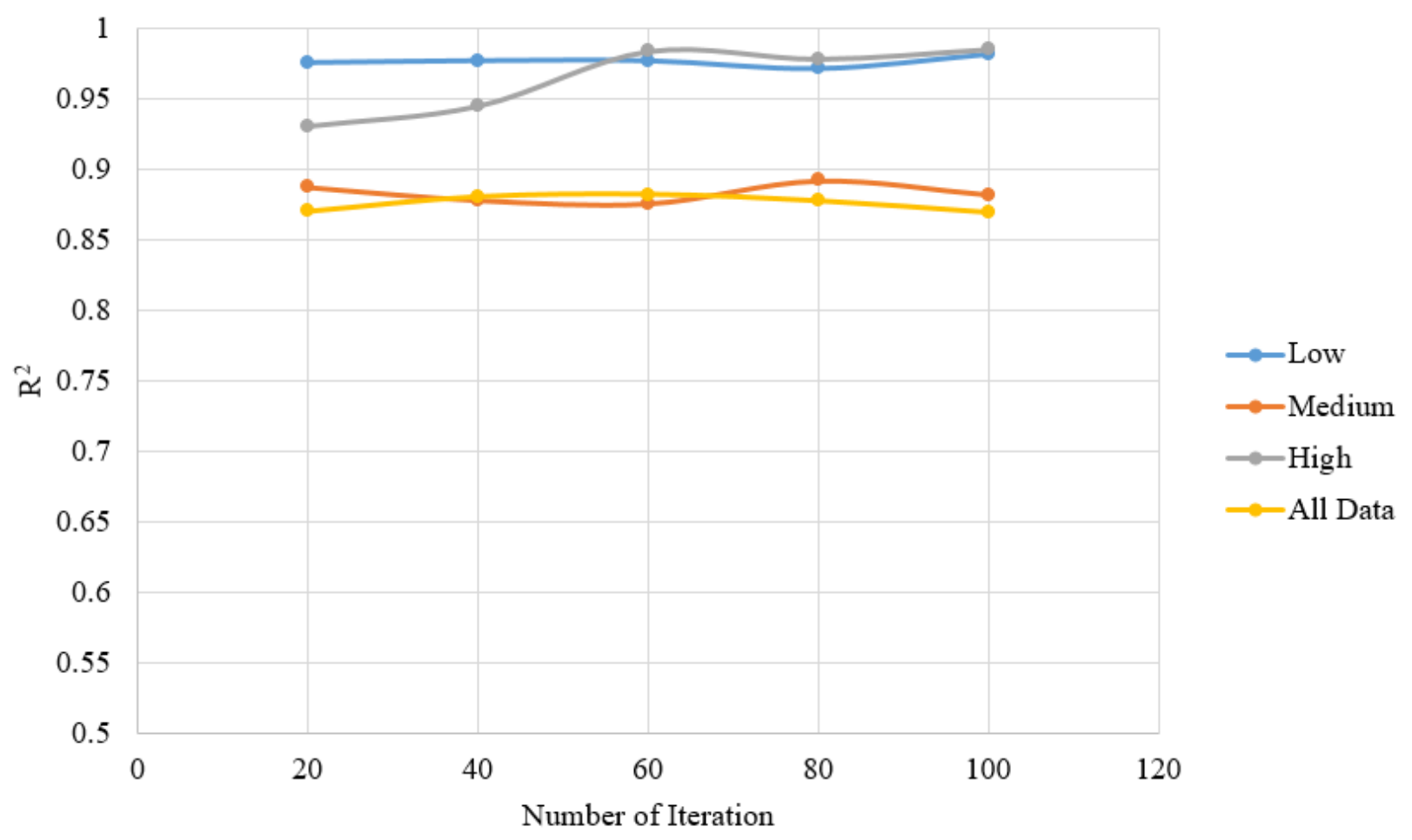

Figure 6 Results of prediction models based on the number of repetitions in terms of $\mathrm{R}^{2}$ 
A general investigation of the results of Figures 6 and 7 shows that like the number of neurons, the number of iteration improves accuracy and decreases the error. Figure 6 shows that for all models, $\mathrm{R}^{2}$ has an upward trend as the number of iteration increases. This is while the error has a decreasing trend in results, indicating the reduction of error. The optimal selection is also applied to these models. For a model designed based on all data, the number of 60 iterations were obtained for optimal state, and for models divided in 3 groups of high, medium, and low based on the rock strength, 60,80 , and 60 were obtained, respectively.

As it was observed in the previous section, leveling provides a better performance in the model constructed based on all data. This shows the division done based on the important characteristic 
in data can significantly help with better recognition of models. Finally, the results of top models are provided in Table 2 .

Table 2 Models proposed for 4 types of prediction models

\begin{tabular}{|c|c|c|}
\hline Best Model & $\mathbf{R}^{2}$ & RMSE \\
\hline Low model & 0.96 & 0.373 \\
\hline Medium Model & 0.91 & 0.714 \\
\hline High Model & 0.97 & 0.313 \\
\hline All data Model & 0.89 & 0.727 \\
\hline
\end{tabular}

Considering models selection based on the rocks strength criterion, these 3 models are assessed and optimized in the next section.

\subsection{Optimization of ROP}

In the present study, the performance of ANN model was improved using $\mathrm{ABC}$ algorithm. Generally, for training ANN, the BP algorithm is utilized. The performance of ANN is reduced due to certain defects. One of the greatest critical problems is catching of the least possible local in the entire search space. Whenever the least possible local is achieved, BP algorithm declares to the systems that these coefficients are the most efficient and hence this is known as a bug in BP algorithm. Under such circumstances, global minimum is best achieved through optimization algorithm. In the present research study, an $\mathrm{ABC}$ algorithm is utilized for optimization of network coefficients and reduction of RMSE errors.

In this algorithm, a set of fresh coefficients are generated for every solution after creating basic coefficients by solving Eq. (1). After computation of values for prediction and error for each 
problem, if there is improvement, the fresh coefficients will take the place of prior coefficients. Alternatively, the coefficients will be improvised and the fresh coefficients will be omitted. The probability is calculated for selecting coefficients and fresh items were generated around the coefficients with better benefit and excellence. The reason behind fine tuning coefficients is that later hardly any queries search at the space and time is not wasted. Through this process, search speed is enhanced and optimization of internal system of $\mathrm{ABC}$ algorithm takes place. In the last phase of the algorithm, if the penalty value of every coefficients approaches a target determined value, then, fresh coefficients will be created randomly.

Considering the results of the previous section in which the models were designed for 3 strength levels, 3 types of optimization were considered for these models. For optimization, it needs to obtain the parameters affecting $\mathrm{ABC}$ algorithm. As aforementioned, the number of bees and the number of iteration parameters affect this algorithm performance. Its other parameters are introduced as coefficients which are less effective. For this reason, the best conditions for selecting factors affecting $\mathrm{ABC}$ algorithm are introduced in Table 3. These parameters are applied to optimization of models.

Table 3 Proper parameters for designing ABC algorithm

\begin{tabular}{|c|c|}
\hline Parameters & Value \\
\hline Number of bees & 200 \\
\hline Number of iteration & 400 \\
\hline Acceleration Coefficient & 1 \\
\hline
\end{tabular}




\subsection{Optimizing Design}

In this section, the optimal models are presented for 3 levels of the rocks strength. Considering the problem conditions, the optimization algorithm can search for the effective parameters, and optimize. The problem defined by this research is the use of 4 parameters to determine ROP parameter. As the compressive strength of rock was selected as a determinant feature, this feature created 3 different strength levels in data. Therefore, data affecting ROP are determined supposing 3 strength levels based on drilling machines characteristics. These parameters, which are shown in Table 1, including RPM, flushing media, and thrust. For this reason, in the intelligent modeling section, some models were designed and developed. To the extent one can improve the accuracy of these models, the accuracy in selecting the optimization models and determining the best conditions increase. Here, the best models of these 3 levels were selected from the previous stage and the optimal parameters of $\mathrm{ABC}$ algorithm which shown in Table 3 were determined. Figure 8 displays the best optimization conditions for these 3 levels. 


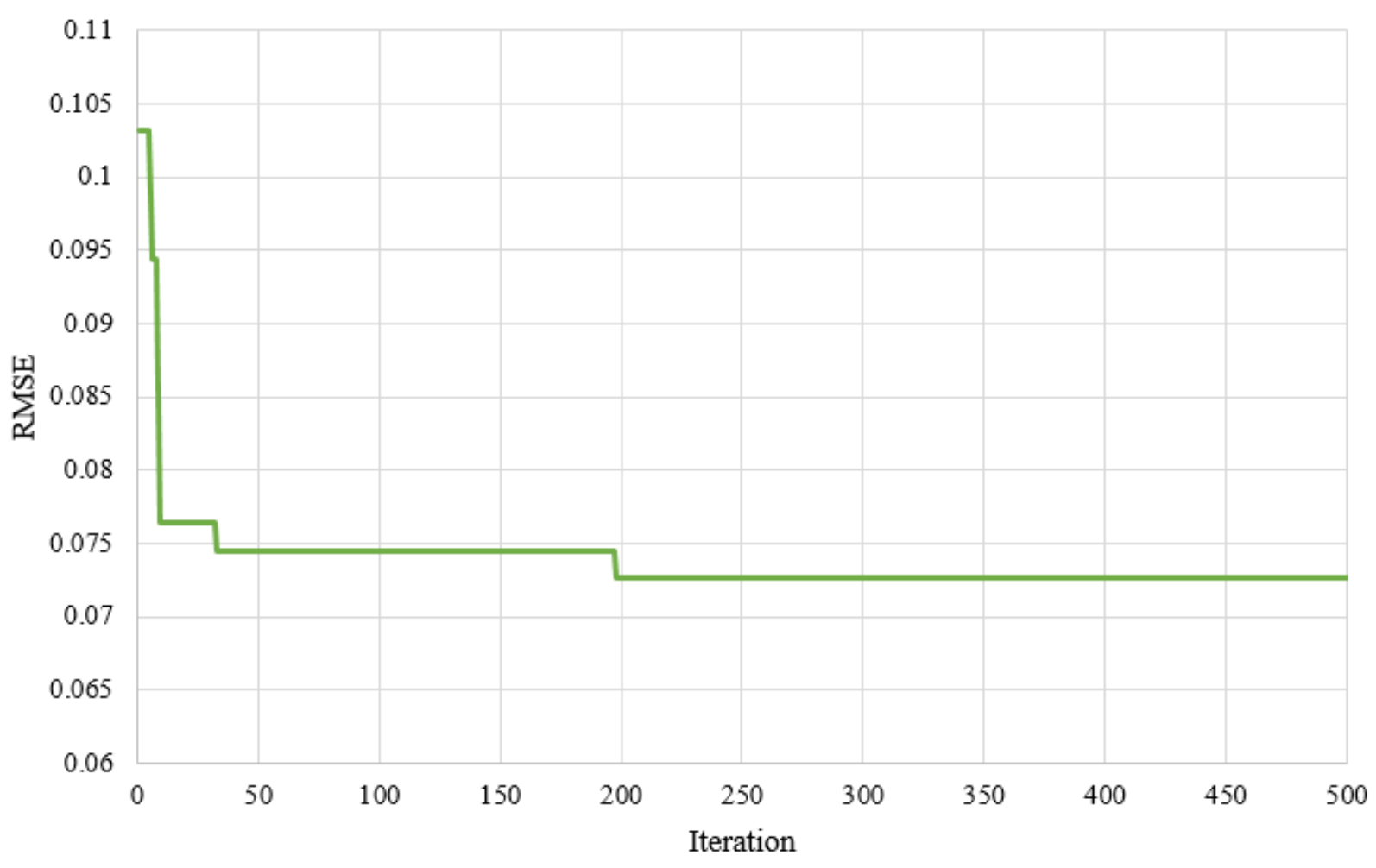

Figure 8 Three models optimization to determine the optimal conditions of drilling machine

The search continues until the system error decreases, that is, ROP can be increased. Considering the prediction model conditions as well as the number of parameters, all 3 models present results. The results show a proper improvement over their initial state. Identifying parameters which are able to determine these conditions for drilling machine is among the important parts of this optimization. Therefore, the effective machine parameters are shown in Table 4. As table displays, the optimal state is shown besides its initial state. The results show that having effective parameters at any moment and drilling based on these parameters can be effective in future drillings.

Table 4 Comparison of initial state and optimal conditions 


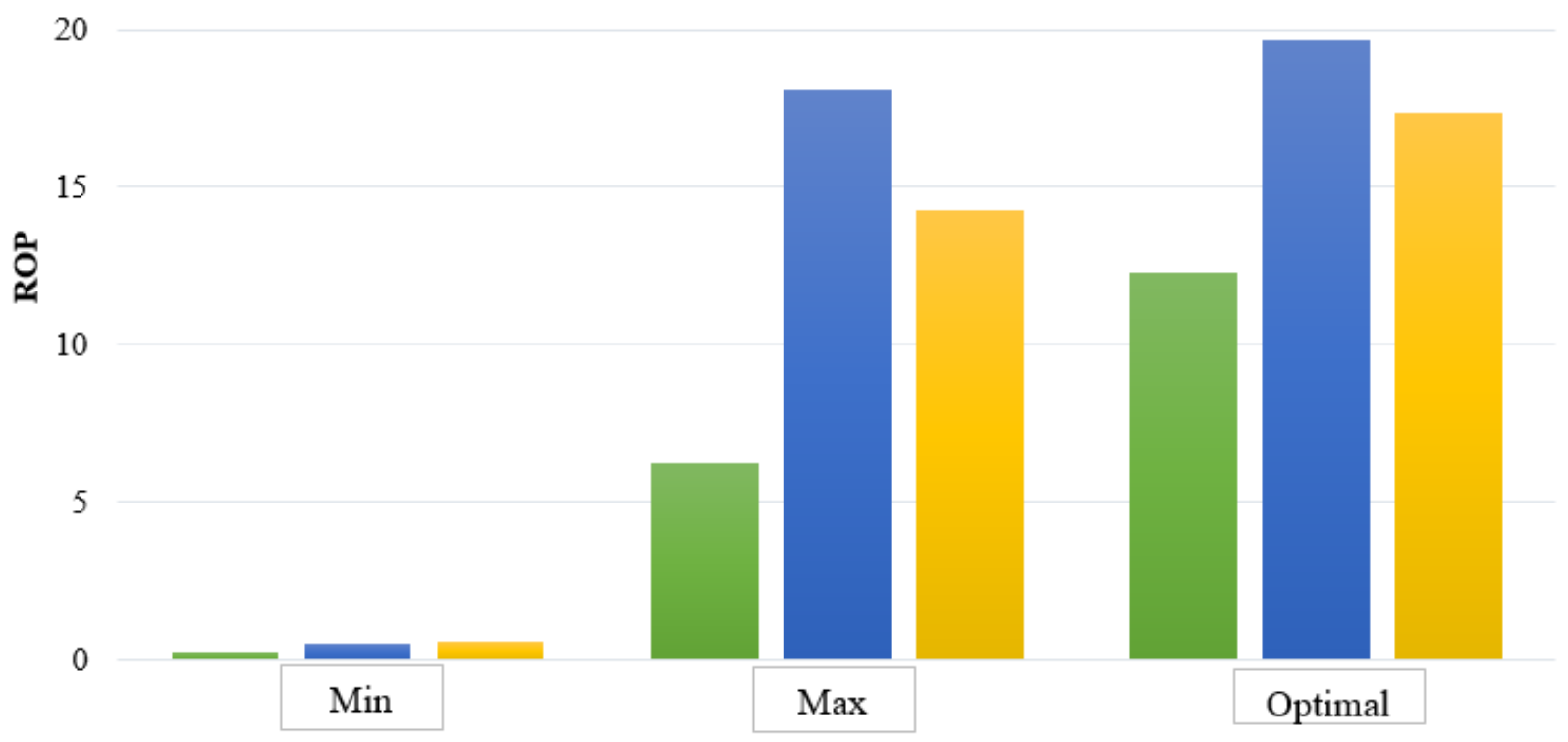

Figure 9 Final results of optimization

\section{Conclusions}

As drilling is always investigated under a variety of conditions, studying its different aspects using new methods can offer a proper perspective in this regard. ROP in drilling systems is a key feature which is capable of determining the performance of drilling. Therefore, in the current research, 618 measurements were done on different samples using different values of the drilling machine. These parameters included Thrust, RPM, flushing media, and compressive strength. Since the compressive strength of rocks was divided into 3 parts, 3 levels of high, medium, and low were introduced for ROP analysis. As this feature was only dependent on the sample, it was selected as 
a criterion for classification. The intelligent models were designed and developed based on these 3 levels as well as all models, and different models were designed to determine the optimal model for each system. Finally, it was found that, selecting simpler models in which samples are closer to each other in terms of strength, can present better models. Therefore, 3 optimal models designed based on compressive strength of the rocks were selected. The ABC optimization algorithm was used to design the problem of ROP. These problem's parameters were determined at the first stage. Then considering the performance of created models based on intelligent systems, drilling optimization was performed to increase the performance of ROP and determine the optimal parameters for 3 levels. Generally, the results showed that under conditions appropriate to each level, effective parameters can be improved based on drilling machine. This research presents the trend appropriate to the measured data. Further studies can be done to expand it.

\author{
Acknowledgements: \\ The authors would like to express their sincere appreciation to reviewers because of their valuable \\ comments that increased quality of our paper. The financial support from the fundamental research funds \\ for the Natural Science Fund of China (Nos. 51879016) and the National Key R\&D Program of China, \\ No.2018YFC1505504) are greatly appreciated.
}

\title{
References
}

1. Bhatnagar A, Khandelwal M (2012) An intelligent approach to evaluate drilling performance. Neural Comput Appl 21:763-770

2. Moraveji MK, Naderi M (2016) Drilling rate of penetration prediction and optimization using response surface methodology and bat algorithm. J Nat Gas Sci Eng 31:829-841 
3. Miller D, Ball A (1990) Rock drilling with impregnated diamond microbits—an experimental study. In: International Journal of Rock Mechanics and Mining Sciences \& Geomechanics Abstracts. Elsevier, pp 363-371

4. Miller D, Ball A (1991) The wear of diamonds in impregnated diamond bit drilling. Wear $141: 311-320$

5. Rowlands D (1974) Rock fracture by diamond drilling.

6. Paona J, Bruce WE (1963) Drillability studiesdiamond drilling. Bur Mines, RI 6324

7. Chugh CP (1992) High technology in drilling and exploration. Balkema

8. Yagiz S, Karahan H (2015) Application of various optimization techniques and comparison of their performances for predicting TBM penetration rate in rock mass. Int J Rock Mech Min Sci 80:308-315

9. Cheniany A, Hasan KS, Shahriar K, Hamidi JK (2012) An estimation of the penetration rate of rotary drills using the specific rock mass drillability index. Int J Min Sci Technol 22:187-193

10. Rostami J (2015) Performance prediction of hard rock Tunnel Boring Machines (TBMs) in difficult ground. Tunn Undergr Sp Technol 57:. https://doi.org/10.1016/j.tust.2016.01.009

11. Yagiz S (2002) Development of rock fracture and brittleness indices to quantify the effects of rock mass features and toughness in the CSM Model basic penetration for hard rock tunneling machines

12. John LP (1994) Influence of RPM and flushing media on the performance of diamond drilling, B. Tech

13. Paone J, Madson D (1966) Drillability studies: impregnated diamond bits. Department of the Interior, Bureau of Mines

14. Rao KU (1993) Experimental and Theoretical Investigation of Drilling of Rocks by Impregnated Diamond Core Bits

15. Rao KUM, Misra B (1994) Design of a spoked-wheel dynamometer for simultaneous monitoring of thrust and torque developed at the bit-rock interface during drilling. Int J Surf Min Reclam 8:145-152

16. Zhao Y, Yang H, Chen Z, et al Effects of Jointed Rock Mass and Mixed Ground Conditions on the Cutting Efficiency and Cutter Wear of Tunnel Boring Machine. Rock 
Mech Rock Eng doi.org/10.1007/s00603-018-1667-y

17. Yang HQ, Li Z, Jie TQ, Zhang ZQ (2018) Effects of joints on the cutting behavior of disc cutter running on the jointed rock mass. Tunn Undergr Sp Technol 81:112-120

18. Ghaleini EN, Koopialipoor M, Momenzadeh M, et al (2018) A combination of artificial bee colony and neural network for approximating the safety factor of retaining walls. Eng Comput 1-12

19. Koopialipoor M, Nikouei SS, Marto A, et al (2018) Predicting tunnel boring machine performance through a new model based on the group method of data handling. Bull Eng Geol Environ 1-15

20. Hasanipanah M, Armaghani DJ, Amnieh HB, et al A Risk-Based Technique to Analyze Flyrock Results Through Rock Engineering System. Geotech Geol Eng 36:2247-2260

21. Gordan B, Koopialipoor M, Clementking A, et al (2018) Estimating and optimizing safety factors of retaining wall through neural network and bee colony techniques. Eng Comput $1-10$

22. Hasanipanah M, Noorian-Bidgoli M, Jahed Armaghani D, Khamesi H (2016) Feasibility of PSO-ANN model for predicting surface settlement caused by tunneling. Eng Comput 32:. https://doi.org/10.1007/s00366-016-0447-0

23. Chahnasir ES, Zandi Y, Shariati M, et al (2018) Application of support vector machine with firefly algorithm for investigation of the factors affecting the shear strength of angle shear connectors. SMART Struct Syst 22:413-424

24. Sedghi Y, Zandi Y, Toghroli A, et al (2018) Application of ANFIS technique on performance of $\mathrm{C}$ and L shaped angle shear connectors. SMART Struct Syst 22:335-340

25. Mansouri I, Safa M, Ibrahim Z, et al (2016) Strength prediction of rotary brace damper using MLR and MARS. Struct Eng Mech 60:471-488

26. Sari PA, Suhatril M, Osman N, et al (2018) An intelligent based-model role to simulate the factor of safe slope by support vector regression. Eng Comput https://doi.org/10.1007/s00366-018-0677-4

27. Armaghani DJ, Mohamad ET, Narayanasamy MS, et al (2017) Development of hybrid intelligent models for predicting TBM penetration rate in hard rock condition. Tunn Undergr Sp Technol 63:29-43. https://doi.org/10.1016/j.tust.2016.12.009

28. Armaghani DJ, Hajihassani M, Sohaei H, et al (2015) Neuro-fuzzy technique to predict 
air-overpressure induced by blasting. Arab J Geosci 8:10937-10950.

https://doi.org/10.1007/s12517-015-1984-3

29. Momeni E, Jahed Armaghani D, Hajihassani M, Mohd Amin MF (2015) Prediction of uniaxial compressive strength of rock samples using hybrid particle swarm optimizationbased artificial neural networks. Meas J Int Meas Confed 60:. https://doi.org/10.1016/j.measurement.2014.09.075

30. Armaghani DJ, Mohamad ET, Momeni E, et al (2016) Prediction of the strength and elasticity modulus of granite through an expert artificial neural network. Arab J Geosci $9: 48$

31. Mansouri I, Shariati M, Safa M, et al (2017) Analysis of influential factors for predicting the shear strength of a $\mathrm{V}$-shaped angle shear connector in composite beams using an adaptive neuro-fuzzy technique. J Intell Manuf 1-11

32. Hasanipanah M, Shahnazar A, Amnieh H (2017) Prediction of air-overpressure caused by mine blasting using a new hybrid PSO-SVR model. Eng with. https://doi.org/10.1007/s00366-016-0453-2

33. Armaghani DJ, Hasanipanah M, Amnieh HB, Mohamad ET (2018) Feasibility of ICA in approximating ground vibration resulting from mine blasting. Neural Comput Appl 29:457-465

34. Mojtahedi SFF, Ebtehaj I, Hasanipanah M, et al (2018) Proposing a novel hybrid intelligent model for the simulation of particle size distribution resulting from blasting. Eng. Comput.

35. Amiri M, Amnieh HB, Hasanipanah M, Khanli LM (2016) A new combination of artificial neural network and K-nearest neighbors models to predict blast-induced ground vibration and air-overpressure. Eng Comput 32:631-644

36. Toghroli A, Mohammadhassani M, Suhatril M, et al (2014) Prediction of shear capacity of channel shear connectors using the ANFIS model. Steel Compos Struct 17:623-639

37. Hasanipanah M, Jahed Armaghani D, Bakhshandeh Amnieh H, et al (2016) Application of PSO to develop a powerful equation for prediction of flyrock due to blasting. Neural Comput Appl. https://doi.org/10.1007/s00521-016-2434-1

38. Koopialipoor M, Armaghani DJ, Haghighi M, Ghaleini EN (2017) A neuro-genetic predictive model to approximate overbreak induced by drilling and blasting operation in 
tunnels. Bull Eng Geol Environ https://doi.org/10.1007/s10064-017-1116-2

39. Teodorovic D (2003) Transport modeling by multi-agent systems: a swarm intelligence approach. Transp Plan Technol 26:289-312

40. Teodorovic D, Dell'Orco M (2005) Bee colony optimization-a cooperative learning approach to complex transportation problems. Adv OR AI methods Transp 51:60

41. Pham DT, Ghanbarzadeh A, Koç E, et al (2006) -The Bees Algorithm—A Novel Tool for Complex Optimisation Problems. In: Intelligent production machines and systems. Elsevier, pp 454-459

42. Karaboga D, Akay B (2007) Artificial bee colony (ABC) algorithm on training artificial neural networks. In: Signal Processing and Communications Applications, 2007. SIU 2007. IEEE 15th. IEEE, pp 1-4

43. Karaboga D, Basturk B (2007) A powerful and efficient algorithm for numerical function optimization: artificial bee colony (ABC) algorithm. J Glob Optim 39:459-471

44. Yang X-S (2010) Firefly algorithm, Levy flights and global optimization. In: Research and development in intelligent systems XXVI. Springer, pp 209-218

45. Karaboga D, Basturk B (2008) On the performance of artificial bee colony (ABC) algorithm. Appl Soft Comput 8:687-697

46. Singh A (2009) An artificial bee colony algorithm for the leaf-constrained minimum spanning tree problem. Appl Soft Comput 9:625-631

47. Garrett JH (1994) Where and why artificial neural networks are applicable in civil engineering

48. Koopialipoor M, Armaghani DJ, Hedayat A, et al (2018) Applying various hybrid intelligent systems to evaluate and predict slope stability under static and dynamic conditions. Soft Comput https://doi.org/10.1007/s00500-018-3253-3

49. Armaghani DJ, Mahdiyar A, Hasanipanah M, et al (2016) Risk Assessment and Prediction of Flyrock Distance by Combined Multiple Regression Analysis and Monte Carlo Simulation of Quarry Blasting. Rock Mech Rock Eng 49:1-11. https://doi.org/10.1007/s00603-016-1015-z

50. Simpson PK (1990) Artificial neural systems. Pergamon

51. Koopialipoor M, Murlidhar BR, Hedayat A, et al (2019) The use of new intelligent techniques in designing retaining walls. Eng Comput 1-12 
52. Dreyfus G (2005) Neural networks: methodology and applications. Springer, Berlin, Heidelberg

53. Koopialipoor M, Fallah A, Armaghani DJ, et al (2018) Three hybrid intelligent models in estimating flyrock distance resulting from blasting. Eng Comput https://doi.org/10.1007/s00366-018-0596-4

54. Koopialipoor M, Fahimifar A, Ghaleini EN, et al (2019) Development of a new hybrid ANN for solving a geotechnical problem related to tunnel boring machine performance. Eng Comput 1-13

55. Saemi M, Ahmadi M, Varjani AY (2007) Design of neural networks using genetic algorithm for the permeability estimation of the reservoir. J Pet Sci Eng 59:97-105

56. Karaboga D (2005) An idea based on honey bee swarm for numerical optimization. Technical report-tr06, Erciyes university, engineering faculty, computer engineering department

57. Koopialipoor M, Ghaleini EN, Haghighi M, et al (2018) Overbreak prediction and optimization in tunnel using neural network and bee colony techniques. Eng Comput 1-12

58. Hornik K, Stinchcombe M, White H (1989) Multilayer feedforward networks are universal approximators. Neural networks 2:359-366

59. Safa M, Shariati M, Ibrahim Z, et al (2016) Potential of adaptive neuro fuzzy inference system for evaluating the factors affecting steel-concrete composite beam's shear strength. Steel Compos Struct 21:679-688

60. Mohammadhassani M, Nezamabadi-Pour H, Suhatril M, Shariati M (2014) An evolutionary fuzzy modelling approach and comparison of different methods for shear strength prediction of high-strength concrete beams without stirrups. Smart Struct Syst, Int J 14:785-809 